\title{
Rhetorical Sovereignty in the Composition Classroom
}

Amanda Moris*

\begin{abstract}
This essay examines the results of a cross-disciplinary experiment at Auburn University in 2008 and illustrates how the guiding theory of rhetorical sovereignty (from Native American Studies) created new storyalities for students in Auburn University's freshman-level core composition class.
\end{abstract}

Keywords: Rhetorical Sovereignty, Composition, University Writing and Indigenous Rhetoric

* Corresponding author: Amanda Moris; Assistant Professor Kutztown University of Pennsylvania (USA); email: amorris@kutztown.edu 
'Water: a Love story' [Linda Hogan] left me in awe of the author's rhetorical talent and personal history. . . The power in her story is the reader's reaction to it; vividly disturbing the psyche clarifies her message.

- Student 1

Leslie Marmon Silko's Storyteller. . .was a story of her heritage, a creation story. It was a story she had heard from her older relatives, a story they wanted to be continued on in future generations. It was a perfect example of what the term rhetorical sovereignty means.

- Student 2

My favorite reading during this semester was Thomas King's "'You'll Never Believe What Happened' Is Always a Great Way to Start," because King's humor grabbed me. It has been one of the many stories I have read this semester that has taught me about writing.

- Student 3

\section{Introduction}

Teaching students the basic concepts behind rhetorical sovereignty and allowing them to use this theory for their own storytelling can connect them in substantive ways to indigenous individuals' contemporary stories and improves their awareness about tribal peoples in general, all the while learning to look at themselves, their families, friends, and communities in new ways. This essay illustrates how the guiding principle of rhetorical sovereignty created new storyalities $^{1}$ for students in Auburn University's freshman-level core composition class, English 1100, during the fall of 2008.

Framing a basic composition course around storytelling may seem common, while including a Native American theoretical concept such as rhetorical sovereignty may seem unconventional. However, it is in the breaking of conventions that social, cultural, political, and educational

\footnotetext{
${ }^{1}$ My term, story(ality) is the result of storytelling in a contact zone that creates or alters reality directly or indirectly via (some type of) language. It relies on true or real stories (rather than works of fiction or pure imagination), and depends on the intellectual and ideological tension between the storyteller and the audience. Responding to these Native American storytellers' insistence on the important role stories play in life, I offer this new term as a way of considering the intentions, goals, and results of storytelling in a contact zone where stereotypes and racist beliefs are in play as legitimate pieces on the chessboard of ideas. In other words, story(ality) is only possible during moments of tension when all are voluntarily participating in the storytelling dialectic.
} 
progress is possible. By providing students a safe contact zone in which to examine their lives and the world around them in a way that both acknowledges students' interests but also teaches them how to relate their experiences to that of Native Americans can work to reduce racial divisions and potentially eliminate the possible perception of American Indians as exotic Others ${ }^{2}$ or as the simplified stereotypes found in sports team names and on product labels.

Constructing collective meaning and personal identity through stories of experience are issues that Native American scholars such as Malea Powell, Angela Haas, Thomas King, and Scott Lyons continue to wrestle with in their works. In particular, Scott Lyons' idea is that rhetorical sovereignty is a people's control of its own meaning through language. To reiterate his definition: Rhetorical sovereignty is "the inherent right and ability of peoples to determine their own communicative needs and desires. . to decide for themselves the goals, the modes, the styles, and languages of public discourse" (CCCC 51.3, 449-50).

Indeed, this idea should not be limited to the operating theatre of Native American Studies. A wider application is possible. Scott Lyons' theory of rhetorical sovereignty offers students of all backgrounds the chance to view their own stories through an experience-grounded lens that originates from a cultural perspective previously unknown to many students. ${ }^{3}$ In fact, the basic composition classroom ${ }^{4}$ is a contact zone

\footnotetext{
${ }^{2}$ Not that all students or all Americans think of Native Americans this way. There are many individuals who have seen and read works by and about Native peoples, worked with indigenous populations, and know the laws and history. However, this goal is still a legitimate one based on my experience - enough people do seem to be a bit in the dark about Native peoples' existence in our modern world and have skewed or incorrect impressions about their cultures that my desire to turn on the light is a valid goal. I don't expect my students to agree or even like what they read, hear, and experience, but I do expect them to consider these texts with an open mind. Conversely, to assume that everyone is equally enlightened and knowledgeable about contemporary Native peoples is equally dangerous. In our increasingly global society, more cross-cultural understanding is needed to improve communication of ideas and expectations across the physical and mental borders in minds and hearts.

${ }^{3}$ Auburn University is a large southern institution with approximately 25,000 enrolled students where I conducted my research for this article. According to the university's Office of Institutional Research and Assessment's Fall 2009 New Student Factbook,
} 
where students' perceptions of reality can be altered and changed by their interactions with Native American nonfiction subject matter, thus creating a new story(ality) for these young adults. The use of rhetorical sovereignty as the guiding theory in the classroom also allows Auburn University students the opportunity to perhaps learn something about themselves, how they project their own stories into the world, as well as how the world attempts to define them as youth, as Southerners, and as women and men.

\section{Theory to practice}

Examining and analyzing various First Nations texts for rhetorical strategies, then using those strategies to create texts provides basic composition students a new way of understanding and experiencing their world. The goal of this class was to give students a better understanding of their own lives by using the idea of rhetorical sovereignty as a framing device. By blending this abstract theoretical approach to experience with the powerful action of rhetorical sovereignty (a people's control of its own meaning through language), students learn practical intellectual skills such as accretive thinking, imagination, and storytelling about family, place, and experience. Short assignments and major papers emphasize awareness and reflection about representations of self, family, community, and place.

The theme, "My Story/Our Story," focuses on exploring intellectual skills that arise from tribal cultures and go beyond linear, and classic logical ways of thinking. The goals of the scaffolded assignments include helping students understand oral tradition and storytelling, learn to construct and maintain a positive self-identity and develop their individual voices. Also, students learn to use storytelling to develop layers of information that gradually develop collective and individual meaning. Specifically, these assignments build students' intellectual skills, introduce them to Native Americans in a new way, as well as teach

enrollment by race averages for 2007-2009 are $86 \%$ white or Caucasian, $8 \%$ AfricanAmerican, 2\% Hispanic, and .7\% Native American. (https://oira.auburn.edu/newstu_factbookFA09.pdf)

4 This theory worked equally well in a World Literature II survey course at Auburn in 2009. 
them new terms and open the door to new experiences as college writers and citizens of this nation. Readings come solely from Native American writers and increased in difficulty and controversy as the semester progressed. Surprisingly, the most difficult, complex, and controversial readings were some of the students' favorites. In particular, Anzaldua's poems "El Sonavabitche" and "We Call Them Greasers" received the most mentions in students' final reflective essays. However, I must reiterate the importance of scaffolding when using unfamiliar cultural texts. Scaffolding is simply building one assignment into the next, like steps leading up to the top of a building. Each assignment builds on the knowledge and skills acquired in the one before. Comfort and familiarity grows steadily and students are rarely blindsided by unknown tasks because each new assignment contains some elements of the prior assignment. This tactic is particularly important when introducing difficult or controversial materials and perspectives. It is especially important in this context with Native American texts because the experiential information embedded in these texts clashes with students' understanding of American experience and history in general and their personal experiences in particular.

Beginning with lighter fare and moving toward the more difficult and aggressive readings allows students a gently sloping path to climb throughout the semester in order to reach the pinnacle, as opposed to just dropping them on the mountaintop and expecting them to know how to traverse the slopes without prior training. Issues surrounding "American Indian ways of knowing," including rhetorical sovereignty, are not the sole domain of Native American peoples, but do offer some productive and interesting opportunities for students to examine and explore their own lives, family and community stories, and to learn how to layer information imaginatively to gradually develop meaning for an outside reader. Specifically, the "American Indian ways of knowing" we used that semester were based on Lawrence Gross's definition in his Wicazosa Review article: Storytelling to maintain a positive self-identity, uniting

\footnotetext{
${ }^{5}$ This phrase comes directly from the title of Lawrence Gross's article in Wicazo-Sa Review (20:2 2005), "Teaching American Indian Studies to Reflect American Indian Ways of Knowing and to Interrupt Cycles of Genocide."
} 
the past and present to create a more positive future, and using imagination and accretive thinking (layering/building information to create meaning - not necessarily linear $a+b+c$ structure). The purpose of English 1100 at Auburn University is to develop students' proficiency with key elements of academic discourse, develop their ability to critically and substantially engage with texts, assessing and analyzing those texts' rhetorical features, and to create a focused thesis statement supported by a variety of primary sources. These goals were certainly accomplished by using storytelling and rhetorical sovereignty, but the process was neither easy nor comfortable.

The southern university classroom might be one of the best-suited locations for such a test with rhetorical sovereignty because my students live with stereotypes placed on them by the rest of the nation and each other. In order to emphasize this stereotype and open a connecting pathway to the stereotypes surrounding indigenous peoples, I start the second class by asking students to get out a piece of paper and divide it into two sections. Then I say, "On the top half of the page, draw me a picture of a typical Southerner." That is the extent of my instruction. I do not specify gender, race, or socioeconomic status. Amazingly, every time I have conducted this drawing experiment (with approximately 175 students total over two years), $95 \%$ of the drawings show a white man wearing a hat (usually a ball cap), a plaid flannel shirt and boots (sometimes cowboy boots, sometimes work boots). In addition, the props usually include a gun, a dog, a truck, and a whiskey jug. The other five percent tend to be simple line drawings of typical Auburn students (Nike shorts and flip-flops, or long shorts and a polo shirt), self-portraits, or Scarlett O'Hara. Without discussing what these visual results imply, I then ask the students to draw a picture of an Indian chief on the bottom half of the page. At this point, recognition of the intended connection usually occurs to about $30 \%$ of the class and those individuals start nodding and chuckling slightly to themselves while drawing a half-naked and shoeless "Indian" man with feathers in his long, dark, braided hair, a bone choker around his neck, a loincloth around his waist with either a bow and arrow or spear and fire as the additional elements (sometimes these characters also get the whiskey jug). 
At the sound of the chuckles, I am quick to add that there is no judgment in what they draw; the image that instinctually comes to mind is the important thing to draw and that we will discuss and analyze where that image comes from. When everyone looks around at their neighbors' images of the typical Southerner, I ask students to raise their hands if what they see visually represents them and their experiences as Southerners. Usually one or two students raise their hands almost apologetically while the rest look embarrassed as they realize they relied on a stereotype that, for the most part, isn't true for them. The disconnect from personal experience that these students feel during the act of drawing the stereotype that comes to their minds compels the discussion into controversial territory - where do these images come from and how are they reinforced and perpetuated by the entertainment industry, media, and even family and friends?

But I'm getting ahead of myself.

\section{Contact zones and resistance}

The idea for this theme grew out of my scholarship working with Native American scholars and intellectuals in academic and nonacademic contexts, particularly when considering Mary Louise Pratt's pedagogical contact zone. Pedagogical contact zones inherently contain challenges, especially when using "unsolicited oppositional discourse" in a composition classroom with traditional rhetorical objectives (Professing in the Contact Zone 15). Not only that, just as Pratt experienced, my theme put "ideas and identities on the line," which meant anticipating "rage, incomprehension, and pain" as well as "exhilarating moments of wonder and revelation, mutual understanding, and new wisdom" - the challenges and joys of the contact zone (Professing 16-17). Pratt lists storytelling, identifying with the attitudes and ideas of others, experiments in transculturation, the redemption of the oral, engaging with suppressed aspects of history (including students' own personal histories), and ground rules for communication across lines of difference as essential elements of cultural mediation (Professing 16). 
The positioning of my classroom as a mediational space that will contain controversial ideas is intended to both warn and comfort students, particularly freshmen, that in college one grapples with difficult ideas and must learn to navigate, negotiate, and articulate opinions and thoughts in new and respectful ways. On one hand, this course philosophy intimidates students because being in college is an overwhelming new experience and few have been directly challenged in precisely this way by a teacher. On the other hand, most of my students usually begin to embrace this liberating and safe environment and learn to express even the most difficult and controversial of thoughts in ways that receive respectful consideration from me and their classmates. This is one of the greatest joys of teaching in a contact zone with challenging material. But the precedent must be set on the first day in written and verbal forms and does not guarantee harmony or easy passage.

Two reviews of Professing in the Contact Zone: Bringing Theory and Practice Together (2002), edited by Janice Wolff, offer competing impressions of this collection of essays that tackle the implications of Pratt's ideas in actual classroom situations. For instance, Gary KochharLindgren suggests in his effusive reaction, "Writing, as an opening of the space of shared understanding, carries with it a utopian hope for the future of the (perhaps) larger space of society itself. Writing creates the possibility of justice" (Pedagogy 5:1 2005, 153) Conversely, Bill Milligan calls the collection a "broad but provocative overview of the practice, theory, and approaches associated with Mary Louise Pratt's metaphor," but concludes that "contact zone theory creates a dangerous environment for the teacher unskilled in its subtleties and nuances" (Pedagogy 5:1 2005, 150). One of the collection's scholars, Richard Miller, provides ample warning about using controversial topics in a composition classroom contact zone. In "Fault Lines in the Contact Zone," an essay that first appeared in College English in 1994 and then in the collection Professing in the Contact Zone (2002), Miller addresses the issue of practical action in the classroom when "unsolicited oppositional discourse" is introduced, students react in unpleasant ways, and then the teacher must negotiate a response. What Miller characterizes is not safe, pleasant, or comfortable. Generally, he examines "the heuristic value of 
the notion of the contact zone when applied not only to student writing, but also to our own academic discussions of that writing" (Professing 123). Specifically, he begins with a student essay titled "Queers, Bums, and Magic" that was first publicly introduced at a 1991 Modern Language Association workshop and that quickly spun off conference panels at future MLA and College Composition and Communication conferences that responded to it. Introducing this student work in his own essay the same way it was fragmented and discussed at these national conferences allows Miller the added opportunity of addressing the problem of contextual absence or making judgments based on partial or contradictory information.

Relevant to my situation was the bold resistance evident in this student writing, the potential professorial responses to it, and the idea that the homophobia and violence articulated by the student writer are "cultural commonplaces" (Miller, Professing 131). Arguably, the frequent absence of Native peoples from our modern American public conversation is also a cultural commonplace that leads to the kind of collective ignorance on display in my students' drawings of an Indian chief. Again, this is not a negative judgment, merely reality showcasing the lack of knowledge that perpetuates ignorance. In my experience, after introducing students to contemporary Native American perspectives, most walk away with new knowledge and a very different idea about ongoing Native presence in this land. Essentially, my approach can create a new story(ality) for students once their preconceived notions about Native absence is challenged and complicated with new information. Therefore, the large-scale ubiquitous lack of knowledge can be corrected

\footnotetext{
${ }^{6}$ According to Miller, "Queers, Bums, and Magic" was "written in a pre-college-level community college composition class taught by Scott Lankford at Foothill College in Los Altos Hills, CA, in response to an assignment taken from The Bedford Guide for College Writers that asked students to write a report on group behavior. One of Lankford's students responded with an essay detailing a drunken trip he and some friends made to 'San Fagcisco' to study 'the lowest class. . the queers and the bums"” (Professing 124). In addition to asking a man they find on Polk Street if he is 'a fag', the students portrayed in the narrative then drunkenly urinate on a homeless person, whom they proceed to kick for 30 seconds before running away to their car to leave the city. "It's a haunting piece," Miller writers, "One that gave Lankford many sleepless nights and one that has traveled from conference to conference because it is so unsettling" (Professing 125).
} 
one class at a time by teachers at all levels if the nonfiction stories by Native American writers are introduced and analyzed frequently and consistently.

\section{Who am I?}

From the first day of class, my students worked with idea of rhetorical sovereignty without using the term or reading an excerpt of Scott Lyons' essay until several weeks into the semester. It was the idea that I wanted them to slowly engage with and very often when we, as teachers, label and define good ideas with unfamiliar terms, students tune out, become bored or disinterested, or lack enthusiasm because the terms overwhelm and confuse. As a result, I'm a big fan of getting students to work with an idea without labeling or defining it first. My statement on the first page of the syllabus that "the framework for considering storytelling in a critical way" would be "rhetorical sovereignty, a term from the field of Native American rhetoric meaning 'a people's control of its own meaning" was all my students needed that first day. It was enough for them to know that a new term would be introduced at some point. This tactic allowed me room to dive into the real work from day one - how does one define oneself or one's group and control that meaning?

My intention in these classes was to adapt Scott Lyons' theory of rhetorical sovereignty to be useful and relevant to basic composition students as they learn to write about themselves, their families, communities and experiences in richer and more concrete ways. Specifically, this theory is useful in helping students to see and understand the interconnectivity and interdependence of their individual identities with the identities of these various groups in which they participate. Rhetorical sovereignty sets up the idea of self- and groupidentification, but it is important to note that rhetorical sovereignty means something different to Native peoples than what it means to a non-Native group of university students in a writing class. It could never mean the same thing to these two very different groups because their material realities and histories are so different. However, this theory has value because it can be usefully adapted to help students review and write 
about their experiences in new and more productive ways, thus increasing their awareness of how their experiences and identities are inextricably linked as they move from self to family to community and back again.

A series of three short assignments introduced students to this idea by first asking them to tell their own stories, witness what another student (a complete stranger that early in the semester) would do with their story, then reflect on the experience of having someone take, interpret, and re-tell their stories in words that were not the original storyteller's own. During class discussion, most students reported being pleased by the stories their peers told because all of the information they had shared with each other was safe and surface. Some students shared fears and memories with a bit of depth and accompanying stories. However, most remained on common ground with details such as where they grew up, what majors they were considering, what their families were like, and names of pets and siblings. This public response to the first short assignment reflected students' desire to remain in unchallenged territory, not wanting to become vulnerable by exposing too many of their personal details to unknown peers. This was to be expected for freshman in their first week of college; in fact, I would surmise that this response would occur even if the students were juniors and seniors. On the first day of class, everyone is sizing up the situation and usually acts with restraint and decorum. However, their written reflections on the process of being represented by someone else's words complicated their in-class shared reactions. Many students indicated that although they were satisfied with how their peers represented their stories, they acknowledged that those were not the stories they would tell about themselves. In the meantime, this assignment established concise and creative storytelling as a primary component for the semester, as well as the expectation that all students would be expected to talk in class, reflect on their own writing, and think beyond the surface details.

The second short assignment leaps into more typical territory, asking students to read two essays that "grapple with identity, perception, and representation issues" written by Native American authors. Far from being secretive about the purpose of this assignment, I chose to be as clear as possible: "The goal is to ease you slowly into the ability to see 
through someone else's lens of experience and be able to not just react emotionally, but also be able to analyze your own reactions to unknown issues and ideas AND relate on some level (empathy)." Being direct, upfront and honest with students has always garnered fairly positive outcomes in my experience, so I knew that this approach must be used in this situation where increasingly contentious writings would be introduced. This time, instead of telling a story of someone else's experience, students read about two Native authors' experiences and analyzed them using my prompt questions. In the first part, key questions included what the author chooses to share and which information seems to be privileged, as well as what differences exist between the author's experience and the student's. The issue of whether an individual has a right to identify himself or herself in a particular way was also an important question that continued to arise - who has the right to tell someone's story and to define that person? What seems like a simple answer (each individual has the right to define themselves in whatever terms and with whatever stories they choose) was thoroughly complicated throughout the semester. One frequent question involved the idea of community and what the individual's responsibility to that community might be, and what happens when the individual and community definitions are different? Also, whose community has precedence? Which individuals get to decide on the stories that will represent the whole group? For being the second week of class, the theme was working well. Then students brought their responses to Gansworth and Francis back to class and their reactions prompted me to introduce rhetorical sovereignty in a more concrete fashion.

In "Identification Pleas," Eric Gansworth (Onondaga) writes about his "identity crisis" trying to walk across the border from Mexico back into the United States after leaving his driver's license on the Texas side in his friend's truck. ${ }^{7}$ The story he tells runs the gamut from the arrogant assumptions of the border guard and the politics of hair in the "Indian academic community" to the problem he faced when neither his

\footnotetext{
${ }^{7}$ This essay appears in Genocide of the Mind: New Native American Writing edited by MariJo Moore (2003). The Lee Francis essay for this assignment, "We the People: Young American Indians Reclaiming Their Identity," also appears in this collection.
} 
tribal identification card nor his university ID were adequate to prove that he belonged in the United States. Gansworth writes about being considered "ethnically ambiguous in appearance," which has caused much confusion in others: "Over the years the odd looks, vague frowns, and unasked questions have become the routine. It has been kind of interesting, existing as a walking, breathing Rorschach text for others' perceptions and stereotype templates. I have been mistaken for Italian, Armenian, Middle Eastern, Hawaiian, Russian, Polish, German, Portuguese, and Jewish, but I am often wrongly assumed to be Latino" (273). This rather bewildering assortment of misidentifications is actually mirrored by many of the Native American stand-up comics. One in particular, Larry Omaha, talks in his "Goin' Native American Indian Comedy Slam"" set about his father exclaiming at his birth, "My god, we had a Korean!" Making these connections across the borders of academe and comedy for my students as they struggled with the idea that anyone could be mistaken for so many different ethnicities was both challenging and rewarding, despite the frequent defensive flare-ups in class. I chose the Gansworth essay because of the ambiguity shrouding the writer's identity within the context of his story - Gansworth is clearly annoyed, but handles the story calmly, assertively, and with humor, which I believed made it accessible for newcomers to Native issues. Students did not react defensively to this text, merely with curiosity and a slight hesitancy as their lack of knowledge and understanding about modern Native peoples became apparent. Constant encouragement seemed useful for students to embrace the exploration of these new issues as they learned to write and reflect about new ideas.

The Francis piece garnered quite a different response. First of all, Lee Francis (Laguna Pueblo) refers to indigenous populations as "the People," with the "P" capitalized. My students noticed this right away and wanted to talk about why he would do such a thing. They were used to proper names and nouns being capitalized, so this privileging of Native peoples in writing disturbed many of them and put them on guard. The power and politics of language and its use is unavoidable, perhaps especially in the contact zone of a composition classroom when

\footnotetext{
${ }^{8}$ Showtime special (2010)
} 
discussing contemporary Native writers' nonfiction narratives. And his very first paragraph helped to reinforce the point of my theme:

For the People, whether urban- or reservation-born, it's really about story. The ancients among the People understood that all of creationseen and unseen - tells story. In the long-ago time, from birth to earth, the People learned about their harmonious place in the order of all creation by listening to and telling story. Their identity was inextricably interwoven in the stories they were told. For Native People, story was and continues to be essential to an individual's identity construction and development. (77)

Francis connects identity to story for Native peoples, especially American Indian youth, in such a direct, persuasive and eloquent way, that I hoped this essay would initiate students' understanding of that connection. Their resistance to the privileging of Native peoples over non-Native by the not-so-subtle use of the capital "P" four times in the first paragraph was something I had not anticipated or foreseen because of my familiarity with seeing such usage in the Native-written texts that I study. The rhetorical move by Francis to establish a sort of prevalence of perception or dominance of Native presence over Euramerican presence was much stronger than I had originally considered. Voices were raised the day we discussed these essays and the students concentrated primarily on Francis's essay as offensive and divisive, whereas Gansworth's garnered sympathy and chuckles. Other terms Francis uses such as "massacre," "disease," "harmony," "balance," "smallpox," "rape," "murder," “abducted," “indoctrinate," "brainwash," "selfishness," "isolation," and "tragedies" captured my students' attention and brought language use squarely to the forefront of our conversations. This was not my intention in my zeal to open my students' minds to others' experiences. Ironically, my students' attentiveness to the impact of language mirrors Scott Lyons' attentiveness to the "duplicitous interrelationships between writing, violence, and colonization developed during the nineteenth century. . . [that] would set into motion a persistent distrust of the written word in English" (CCC 51:3 449). 
Granted, my students were not picking up on the same implications that Lyons discusses, but the fact that Francis wrote in English and used terms that call violence to mind, thus drawing the reader's attention to that connection, and the fact that students found those written words disconcerting gave me another pathway to helping them understand Lyons' theory. Clearly, my choices had been more challenging and complex than I had anticipated, so I found myself having multilayered inclass conversations discussing such writing issues as the importance and impact of word choice on the reader, the author's perception of reality versus the reader's perception, the impact that the first paragraph of an essay can make, and why Indians were still so angry because this was all in the past after all, right? Sadly, as a result of these surface detail conflicts, we never discussed in-depth the more interesting (to me) story/identity connection that Francis makes in relation to Indian youth of today and his argument, "It is in the stories, old and new, where urban Native youth will be able to reclaim their Native identity" (79). It was an eye-opening lesson for me to be less cavalier about the opening texts I choose and also prompted me to introduce Scott Lyons and an excerpt from his essay defining rhetorical sovereignty.

To say that students struggled with Lyons' essay would be an understatement, primarily because their active resistance to the subject matter had flared up thanks to the Francis essay and they were wary. I worked for days to break down their resistance by explaining rhetorical sovereignty as many different ways and using as many different examples as possible to make it clear. What became clear, however, was that many students refused to accept the new information; active resistance to education. Respectfully breaking down students' resistance is essential to helping them learn how to empower themselves to learn about their own stories of experience. This idea of self-empowerment in the composition classroom through using personal experience and the recognition of the individual and communal self is an ongoing conversation in composition studies. In fact, John Rouse and Edward Katz write about these intersections of power and self in the writing 
classroom in Unexpected Voices: Theory, Practice, and Identity in the Writing Classroom (2003). ${ }^{9}$

In chapter three, "Everyone's Secret is the Same," Rouse and Katz debate via their letters about the virtues and difficulties inherent in having students talk and write about their personal experiences as they read unfamiliar texts that both challenge and reinforce certain cultural values, how to respond when students reveal extremely personal details and the challenges of negotiating student in-class interactions when two individuals "actively preach their conflicting views of life at each other" because "they're not making it any easier to build the loving classroom" (53). Katz is the writer of this last quote and he was writing at a time when his South African school, University of the Western Cape, was experiencing a fairly violent ongoing student boycott of classes in protest of the university withholding food credits from students who hadn't paid their fees. This material reality heightened the tension and conflict in his classroom as students discussed and explored their experiences in conversation and in writing, but also represented a fundamental truth that Katz puts forward for Rouse's consideration. He writes, "In a sense, all reality is part of the human spirit. What do you think of that?" (55) Rouse responds by addressing the questions raised by Katz, requesting an update from that "unquiet place," and by reporting on the "rather ordinary, undramatic events" in his life and classroom (55). In particular, Rouse suggests that Katz "think of the classroom as a field of action where you create a situation in which all those present are involved in the making of new experience, and so are exposed along the way to the possibility of embarrassment or failure. There's a risk involved, and why

\footnotetext{
${ }^{9}$ This book considers how teaching is a performance and how schooling worldwide "directs people to their individual improvement rather than that of the group," as well as broader issues in composition studies such as academic literacy, expressive and cognitive approaches to the teaching of writing (x). The method is an exchange of letters through which a scholarly conversation occurs across vast physical distance as the authors share their classroom experiences with each other, ask questions, and respond to each other. The two writers hail from very different backgrounds: South African and American, and their personal teaching experiences and interactions with students in the composition classroom are used as examples to ground their claims. Essentially, Rouse and Katz propose that value of narrative pedagogy "as students find a direction or activity suggested by their own concerns and ongoing lives, so that afterward they have a story to tell of their experience together" (ix).
} 
should anyone there be exempt or privileged?" (56) The ideas that these two professors are discussing relate to my use of rhetorical sovereignty in the composition classroom in the following ways: 1) helping students find their voices and learn how to productively express their experiences is a difficult and dangerous undertaking with only the potential for a positive result, and 2) this undertaking is worth the risk inherent in the process as students and teachers converse and conflict, but don't run from the challenge of addressing difficult subjects in the composition classroom.

Simultaneously with my students' expression of their own personal experiences, they were introduced to additional texts from an unfamiliar perspective, which challenged them and threw the stark light of self-reflection on those personal experiences. Specifically, some students were responding to the introduction of "unsolicited oppositional discourse" in the context of a classroom contact zone, judging the information to be irrelevant, and deciding to resist understanding. In hindsight, I attribute this to not only my selection of the Francis essay, but also to my introducing it too early. Had I chosen an essay by Thomas King or N. Scott Momaday or Leslie Silko ${ }^{10}$ to companion with the Gansworth piece instead, I truly believe our discussion of rhetorical sovereignty, its origins, its purpose, and its necessity would not have been as uncomfortable for any of us.

To create a new story(ality), the participants must voluntarily enter the storytelling dialectic with the author and my facilitation of this objective was hindered by the fact that students were in a core class and not there by choice, and also by my selection and assignment of the Francis text without warning my students what they should anticipate finding there. It is important to note that most basic composition classes are core requirements of a university education, therefore, this classroom is uniquely situated as a contact zone because of this power differential students generally do not choose to be there; the university requires them to be there, setting the students immediately at odds with the teacher before any discussion or writing is accomplished. Professing in the

\footnotetext{
${ }^{10}$ These writers were introduced after short assignment \#2, but before our discussion of Lyons' article and theory.
} 
Contact Zone, the collection that I have cited frequently throughout this essay, is one of many excellent scholarly texts that presents varying perspectives and scholarly practices within the contact zone of the basic composition classroom. ${ }^{11}$ I argue that story(ality) can be achieved even within this type of contact zone where students are not there voluntarily because the grappling and clashing of ideas that occurs in the composition classroom set the stage for students to learn and understand a new sense of reality as it relates to themselves, their families, and their communities.

By asking students to make connections between rhetorical sovereignty and owning their own meaning within their lives and experiences, I encourage them to learn about themselves through a theoretical lens that is grounded in experience. Thus, I discovered my greatest diffusion tool - anytime the conversation started getting a little too political or heated for the rest of the semester, I would guide the conversation (sometimes abruptly) back to the students' own lived experiences. In addition to circling around the idea of rhetorical sovereignty, I also spent several class days working on basic storytelling strategies and tactics. Not only did students watch and respond to an Ira Glass Youtube video ${ }^{12}$ in which he explains the two key components to storytelling (anecdote and a point of reflection), they also considered the similarities and differences of the indigenous authors they had encountered so far to their own experiences. By September 16, 2008, the day we discussed Scott Lyons and his article on rhetorical sovereignty, students had read and responded to selections by Eric Gansworth (Onondaga), Lee Francis (Laguna Pueblo), Thomas King (Cherokee/Greek), and Leslie Marmon Silko (Laguna Pueblo). This is how we entered the first two major projects of the semester.

${ }^{11}$ See works by Patricia Bizzell, Min Zhan Lu, Gloria Anzaldua, bell hooks, Peter Elbow, Fan Shen, Keith Gilyard, Mike Rose, and Victor Villanueva, to name a few.

${ }^{12}$ Ira Glass produces "This American Life," a weekly public radio show focused on "mostly true stories of everyday people, though not always" for PBS (thisamericanlife.org). Glass's storytelling lecture was extremely useful for my students because he is such a friendly and honest journalistic storyteller: (http://www.youtube.com/watch?v=n7KQ4vkiNUk) 
The major projects are scaffolded to change students' perspectives and perceptions slowly over the course of the semester by introducing a new layer of information with each assignment. Project One asks students to examine themselves through others' eyes, which achieves the objective of maintaining a positive self-identity through story; Project Two asks students to immerse themselves in their families' stories and histories by interviewing their oldest lucid relative, which achieves the objective of understanding the oral tradition and stories of their own families; Project Three asks students to enlarge their view to consider one of their nonfamily communities and their role in it, which achieves the objective of learning collective meaning as a member of a group; and finally, Project Four takes all of the analysis done on self, family, and community and asks students to apply what they've learned to analyzing a Gloria Anzaldúa reading and then analyzing their own analyses to help students see how differently they read and assess texts when they are required to look more than once. This last project brings all of the "American Indian ways of knowing" together with rhetorical sovereignty as the underlying theory in order to create a new story(ality) for students about themselves and about Native peoples. At the end of the semester, more students walked away as allies of Native American peoples because of the changes in perception they experienced.

For instance, Project One asks students to "enter a dialogue with others and then re-envision that dialogue in writing." The most challenging element was not the three interviews students conducted, but obtaining the criticism about themselves from their families and friends, as directed by the assignment. Many students chafed at the idea and some of the individuals they chose to interview also resisted, not wanting to criticize the student in such a public forum as an English assignment. However, receiving honest criticism gave the students something substantive to write back against, giving them a tiny bit of experience with that sort of intellectual tug-of-war that is so familiar to those of us in the academy, and especially to Native American writers who constantly write back against how non-Natives perceive them. Lyons writes, "Discourses of resistance and renewal have never ceased in Indian country, and these marginalized narratives of the continuing struggle for 
Indian sovereignty are making themselves more and more visible in public representations and talk. It's worthwhile to note how to much of this struggle. . has taken place at what we might call the colonized scene of writing: a site of contact-zone rhetoric at its fullest" (CCCC 51.3, 453). In order to fully grasp what rhetorical sovereignty means to Native scholars, students who are completely unfamiliar with contemporary and historical Native American issues must be gently lowered into the maelstrom. If I was to drop them unprepared into Gloria Anzuldúa or Vine Deloria, Jr., students would likely be unresponsive and shut down faster because these two writers are bold, confrontational, and directly challenging to a knowledgeable reader. My tactic of making these experiential and writing comparisons are meant to integrate new knowledge and perspectives with students' existing knowledge in an effort to grow and improve the baseline. In this way, Anzuldúa and Deloria are not nearly as intimidating or discomfiting.

In addition to writing back against criticism, students also flexed their latent creative storytelling skills during Project One. The finished forms of the dialogues included a play, a Dr. Phil script, a Jerry Springer show, a "Jiminy Cricket" subconscious narration, a family Facebook message exchange, and an episode of the Crocodile Hunter, just to name a few of the imaginative approaches taken. Although some might assume that with all of these creative juices flowing, the main critical assignment objective would become lost, the opposite was true. Because students had a bit more creative license, they also took their thoughts and analysis further than they would have in a traditional academic essay. For example, student 4 wrote in the reflective portion of Project One:

I was sitting alone at the library at Auburn when I realized that I'm almost an adult. I'm to the point where I am going to have to make all my decisions about my life on my own. I thought this point was either going to feel triumphant or terrifying; but it is regrettably neither. All it means is that I am alone, for the first time in my life I have no one who truly knows everything about me here.

And now I can be who I want to be. But, who exactly do I want to be? I want to be happy and successful. I want to be the person my grandmother was. I am not sure how to be more like her; but I'm going to figure it out if it's the last thing I do. 
Self-identity was the primary issue in Project One and students like this one came away with surprising discoveries that helped further self-awareness. Some, like Student 5, had a very introspective and poetic response to this assignment:

I am not the best at anything, although I wish I could be. I am a people pleaser that cannot make decisions. The simple beauties of the earth are how I remember who I want to become. And most importantly, I love to love.

"This is me," I tell Nature. She always accepts me for the person I am. Without questions, she chooses to look past my many faults. I look up to the sky and give a slight smile. I see my identity is painted with the clouds.

Conversely, Student 1 experienced a particularly brutal awakening that he wrote about in his reflection:

This assignment presented a rare opportunity to ask people close to us important questions that might otherwise go unasked and forever unknown. For example I had always thought I was a fairly diplomatic person when in fact I was the opposite. I thought just because I can argue well and speak somewhat elegantly that meant I was diplomatic, when in reality I was abrasive, aggressive and rash in attempting to get people to see it my way. But through my talks with my [family] I came to realize that was a real weak spot in the way I deal with people.

It's a two sided sword because I judge people's intentions quickly and can usually tell what they are trying to say or get done. But my impatience leads me to not seek the subtle diplomatic way of persuasion but the overt and offensive means; which ends up worse than if I had just kept my mouth shut. I'm really glad to have gained this perspective on my identity and how I deal with people, and can now start becoming a better, less offensive, colleague, friend, or opponent.

As students' self-awareness grew, their eyes started opening and seeing others around them in new ways. The way the students achieved this expanded understanding was by interacting with rhetorical 
sovereignty as a guiding principle and by considering the first-person stories of experience from the Native American perspective. Seeing their own experiences through this uniquely Native American lens helped students see the intricate interconnectedness of their own lives in a clearer and more complicated way. Further, students' willingness to speak up and write about the difficulties they experienced in tackling these major projects suggests that freshmen can be trusted with controversial and challenging ideas. Raise the bar as a teacher and students will follow, especially as they see results like the ones above.

\section{Project 4}

On November 11, 2008, we entered the final phase of the semester during which students grappled with chapters and poems from the third edition of Gloria Anzaldúa's book Borderlands/La Frontera: The New Mestiza. Beginning with the preface to the first edition, students then proceeded through "We Call Them Greasers," Chapter Two, "El Sonavabitche," "To live in the borderlands," and Chapter Seven. The three poems were read in class and immediately discussed, whereas the chapters were assigned as homework and then discussed in the next class meeting. Project Four asked students to take their analytic abilities with self, family, and community combined with the idea of rhetorical sovereignty to critically analyze one of these selections in a formal academic essay. The second part of the assignment was to analyze students' own analysis in the Project Four part one essay in order to find out why they chose certain elements to focus on, why they reacted the way they described, and to figure out if, upon a second reading of the chosen text, they had a different response. This multilayered assignment with concrete and abstract intellectual goals intimidated students, but they asked questions and received help from me. The results were so rich that I continue to use this reflective process approach in my new position at Kutztown University in Pennsylvania. As student 12 learned after reflecting on Anzaldúa's stories of experience,

I understand that there is a world of difference between the American culture and Anzaldua's culture, but the beautiful thing about being a part of a community or culture is the accepting nature of all those 
around you. Every community is comprised of so many people who share many of the same ideas, but every community is like a puzzle. All of the pieces of a puzzle work together to make a beautiful picture, but every piece is so different. A community, whether they realize it or not, is more different behind closed doors. If your own community is not accepting of you, then who will be?

Discoveries like this transcend the composition classroom and change how students think about themselves, their families, their communities, as well as communities and individuals with very different life experiences. Improving cross-cultural understanding while teaching basic writing skill sets and helping students see and understand their own experiences as less simplistic and more complicated than they had previously considered them to be has value because education is not a one-sided or one-storied experience and it is important to introduce students to as many different perspectives as possible in college so they are not blindsided by those different perspectives after they graduate. Essentially, when students understand that both/and is the driving idea instead of either/or, they start to appreciate the complexity and depth of their shared experiences with authors who initially seem so culturally different. However, not all discoveries are positive and student responses are not always what we wish them to be. Student 9 admired Anzaldúa's precise logic and deep emotional appeals to her readers in Chapter Two, but his reflection reveals the depth of his personal judgment:

Anzaldua was one of the biggest man haters and she was a little crazy and irrational at times. I think I came to the conclusion of this because I realized a lot of the stuff that she was doing was just complaining about how things are not perfect for her and how everyone has it better, she never sat back and really looked at what good there was in her life.

As imperfect as the writing may be, this student's response is legitimate. First, not every student who goes through a composition course under these circumstances is going to leave the experience with an entirely different attitude or perception of reality related to self or others. All I expect my students to do is consider the subject matter, consider the 
perspectives, and attempt to honestly respond to them. Responses like this one may not validate what some might consider to be an "enlightened" perspective, but it is honest. Students who fully completed the tasks as assigned wrote complex, but equally honest and complicated, responses. However, that is one of the greatest challenges for any teacher - how to get the students to fully engage with an assignment? One added obstacle in this case was subject matter that many students deemed irrelevant to their lives. We had conversations in many class periods about how and why this subject matter was relevant to their lives - from their lack of knowledge of an entire group of people still existing in this land to the fact that they can relate to the stories about family and community told by these authors who at first seem so different - in the end, the students did learn and many did understand that many of the stories they read connected to them personally on some level, but it was a struggle all semester long to help them understand why knowing about Native American contemporary experiences are relevant to them. These stories were not initially familiar or comfortable for students to read and hear - the stories took students way outside their comfort zones, which should always a goal in the classroom because it assists students' selfempowerment.

Pedagogically, my teaching style borrows many tactics from critical pedagogy, which owes its theoretical underpinnings to Paulo Freire, whose radical ideas in Pedagogy of the Oppressed (1970) started the critical pedagogy movement. Freire argued that there is no such thing as a neutral education process and Freire's conviction that every human being, no matter how "ignorant" or submerged in the "culture of silence" he may be, is capable of looking critically at his world in a dialogical encounter with others...[he or she] just needs the right tools. (12-13) In 1992, Ira Shor develops and explores critical pedagogy in practical classroom situations in Empowering Education: Critical Teaching for Social Change, in which he explores education as a political system, the different types of themes that lead to critical thought, and resistance and empowerment in the classroom. He argues that "students need a challenging education of high quality that empowers them as thinkers, communicators, and citizens" (10). Further, the "teacher is the person 
who mediates the relationship between outside authorities, formal knowledge, and individual students in the classroom. Through day-to-day lessons, teaching links the students' development to the values, powers, and debates in society" (13). And the methods for introducing these debates and materials are only three, according to Shor: "Teachers can present knowledge in several ways, as a celebration of the existing society, as a falsely neutral avoidance of problems rooted in the system, or as a critical inquiry into power and knowledge as they relate to student experience" (14). Critical pedagogy, therefore, informs my teaching style and textual choices when designing a composition class with such a perspective as rhetorical sovereignty, storytelling, and "American Indian ways of knowing," especially when those selected texts show experiences that are so vastly different from students' own knowledge and understanding of the world.

\section{Final perceptions, lessons learned, and implications}

Each assignment during Fall 2008 was an unconventional anecdote with a point of reflection as students learned the foreign concepts of rhetorical sovereignty, "American Indian ways of knowing," grappling with identity on four levels: self, family, familiar community, and unfamiliar community. Looking in and looking out, acting, speaking, writing and reflecting, students layered new knowledge atop old, changed their perceptions and perspectives, and came away from the semester with a more vibrant attitude about writing and the potential of stories to abolish misconceptions and stereotypes, as well as experiencing a new story(ality) about Native peoples in this land. Their perception of reality changed because they responded to the challenging and controversial content that I required them to explore. They had no escape and no safety net and yet responded to the challenge day after day. The overall success of this approach to basic composition suggests that it should be employed more often and in more composition classrooms.

Despite the difficulties I encountered with this subject matter and underlying theoretical approach, Mary Louise Pratt reminds us that contact zones are "social spaces where cultures meet, clash, and grapple with each other, often in contexts of highly asymmetrical relations of 
power." Furthermore, Min Zhan Lu suggests that conflict and struggle are not necessarily the enemy of Basic Writing (College English 1992), but rather, education is a process of repositioning. And I saw this repositioning in my students as they grappled and clashed with ideas and cultures that were so completely foreign to their experiences. Consider some of their written remarks about what they learned as a result of this composition contact zone:

Student 2: This class has helped me discover a side of me that I did not know of and has opened me up more as a person. Stories are what make up our lives. They are what help shape us into who we are now. They are how others learn about us and our identity. It is how I learned so much about my grandmother and Gloria Anzuldúa. Stories, I have learned, are the things that have given me my identity.

Student 8: This course forced me to look deeper than I had ever bothered to look before at my family, my community, and myself. By looking closer, I found out things that I had not known before. My view on Native Americans also changed. Even though I am part Native American (Cherokee, represent!), the most I had learned about my roots was in Indian Education, which was more like Native American arts and crafts time than an educational class. I knew of the harsh ways Native Americans were treated and I knew some of their stories, but the readings showed me Native Americans from a Native American point of view, instead of the Americanized versions of them. My perception changed because I had never really had my own perception of these things.

Student 6: I have learned about the art of telling stories. I have come to see that rhetorical sovereignty is what makes a person's story unique and individually theirs. It is the act of making a conscious decision about what they are going to say and the tone in which they are going to say it. I have learned that someday, I will be remembered by my grandchildren. I want to give them something important to remember.

Student 1: I am in awe of the way you laid out this class. It feels like I was just annihilated by a surgical chess-master. Saying under her breath "check-mate" then nonchalantly walked away. The check mate was the epiphany I reached when writing this paper. It became clear to me, a panoramic image flashed through my head where the short 
assignments, storytelling with items, rhetorical sovereignty, the three projects focused on identity in different roles, and the expectation to go beyond one's natural ability to think and rhetorically analyze a 3/4 English social theory, and finally a meta-cognitive exercise that analyzed our own analysis (which itself pushed me further than I had ever gone) until here. Although I did terribly in terms of grades, I did really learn a lot and grew as a reader, writer, and thinker because you were critical of me, that's the only way we grow so THANK YOU SO MUCH and here we are and as usual.... way over the word limit.

\section{Conclusion}

In final summation, as my students discovered, intersections of experience cross cultural, social, economic, and political divides and can be bridged within the context of a basic composition classroom contact zone, as long as the students and teacher become willing participants in the pursuit of this goal. Students started off as unwilling and resistant participants because the Auburn University composition course is mandatory, thus stripping students of a choice. However, as the course progressed and the ideas of rhetorical sovereignty, the practice of firstperson nonfiction storytelling about lived experiences, and new knowledge about Native American perspectives converged, students came away with a new respect for themselves, their families and communities, and the fundamental importance of knowing how to define themselves in each of these groups. Ultimately, this can be an achievable goal in any writing classroom whether students are there by institutional requirement or by choice: Story(ality) thrives when students begin to understand, share, narrate, and write the truths available to them as they consider, test, and use alternative perspectives and unfamiliar stories. 


\section{References}

Anzaldua, Gloria. (2007). Borderlands/La Frontera: The New Mestiza. $3^{\text {rd }}$ ed. San Francisco, CA: Aunt Lute Books.

Freire, Paulo. (1970). Pedagogy of the Oppressed. Trans. Myra Bergman Ramos. New York, NY: Herder and Herder.

Glass, Ira. (2009). "Ira Glass on Storytelling \#1.” Youtube.com. kentj1. 13 Aug 2006.

Gross, Lawrence. (2005). “Teaching American Indian Studies to Reflect American Indian Ways of Knowing and to Interrupt Cycles of Genocide." Wicazo Sa Review 20, (2): 125-45.

King, Thomas. (2003). The Truth About Stories: A Native Narrative. Minneapolis, MN: University of Minnesota Press.

Lu, Min-Zhan.(1992). "Conflict and Struggle: The Enemies or Preconditions of Basic Writing?” College English 54, (8): 887910.

Lyons, Scott. (2010). X-Marks: Native Signatures of Assent. Minneapolis, MN.

Idem. (2000). "Rhetorical Sovereignty: What Do American Indians Want from Writing?" College Composition and Communication 51, (3): 447-468.

Moore, MariJo, ed. (2003). Genocide of the Mind: New Native American Writing. New York: Thunder's Mouth Press.

Pratt, Mary Louise. (1991). "Arts of the Contact Zone." Profession 91: 33-40.

Rouse, John and Edward Katz. (2003). Unexpected Voices: Theory, Practice, and Identity in the Writing Classroom. Cresskill, NJ: Press.

Shor, Ira. (1992). Empowering Education: Critical Teaching for Social Change. Chicago, IL: University of Chicago Press.

Student writings. Engl 1100: Basic composition. Auburn University, 2008.

Wolffe, Janice M., ed. (2002). Professing in the Contact Zone: Bringing

Theory and Practice Together. Urbana, IL: National Council of Teachers of English. 